\title{
TRADISI MADDOJA BINE MASYARAKAT DESA ANABANUA DI KABUPATEN BARRU
}

Edika Syamsurya

Universitas Negeri Makassar, Sulawesi Selatan, Indonesia.

Email: edikasyamsurya1968042006@gmail.com

\begin{tabular}{ll}
\hline INFO ARTIKEL & ABSTRAK \\
\hline Diterima & Tulisan ini membahas tentang tradisi maddoja bine di masyarakat Desa \\
10 Agustus 2021 & Anabanua, Kecamatan Barru, Kabupaten Barru. Dari asal katanya, \\
Direvisi & maddoja yaitu berarti begadang atau tidak tidur, sedangkan bine artinya \\
20 Agustus 2021 & benih. Petani yang melakukan tradisi maddoja bine akan akan untuk \\
Disetujui & menjaga benih padi yang sedang direndam, sebelum ditabur (dalam istilah \\
4 November 2021 & sehari-hari masyarakat Desa Anabanua disebut ma'gugu) di sawah \\
Kata Kunci: & keesokan harinya. Sambil mengisi waktu pada malam maddoja bine \\
Tradisi, Bugis, & tersebut, masyarakat biasanya menikmati hidangan kue-kue tradisional \\
Maddoja bine & bugis yang khusus disediakan untuk acara maddoja bine. Tulisan ini \\
& bertujuan agar kita bisa tau tanggapan masyarakat mengenai tradisi \\
& maddoja bine khususnya di Desa Anabanua, Kecamatan Barru, Kabupaten \\
& Barru dan juga untuk mengetahui nilai-nilai yang terkandung dalam tradisi \\
& maddoja bine di Desa Anabanua, Kecamatan Barru, Kabupaten Barru. \\
& Jenis penelitian yang dipakai dalam jurnal ini yaitu metode kualitatif \\
& dimana kita sebagai peneliti bisa mendapatkan sebuah informasi melalui \\
& tahap wawancara. Hasil yang diperoleh dalam penelitian ini adalah \\
& diharapkan dapat menambah dan memperkaya literatur dan bagi \\
& mahasiswa yang mengadakan penelitian serupa serta menambah \\
& pengetahuan dan memberikan pengalaman baru mengenai tradisi maddoja \\
& bine.
\end{tabular}

\section{ABSTRACT}

This research examines about the maddoja bine tradition in the Anabanua village community, Barru District, Barru Regency.Based on the origin of the word, maddoja means 'to stay up or stay awake, not to sleep'; bine means'seed. 'Farmers who carry out maddoja bine will stay awake at night waiting for the soaked rice seeds, before sowing (in everydays terms the people of Anabanua Village are called ma'gugu) in the rice fields the next day. Whilw filling the time on the night of the maddoja bine, the public usually enjoys traditional Bugis cakes which are specially prepared for the maddoja bine event. This paper aims determine the public's perception of the maddoja bine tradition in Anabanua Village ,Barru District Barru Regency and also to find out the valued contained in the maddoja bine tradition in Anabanua Village, Barru District,Barru Regency. The type of research used is a qualitative research method through interviews. The results obtained in this study are expected to increase knowledge about

Keywords: literature and for studenttd who do research as well as add and provide Tradition, Bugis, new experiences for the Maddoja bine. maddoja bine tradition. 


\section{Pendahuluan}

Setiap daerah di Indonesia pasti memiliki budaya. Kebudayaan tercipta karena jiwa dan otak manusia yang dimanfaatkan sebagai sesuatu untuk memuaskan keberadaan fisik dan dunia lain masyarakat umum. Cara hidup adalah sebagai berbagai macam pemikiran, nilai, pemikiran, standar, dan latihan yang kompleks, khususnya kondisi yang dirancang dalam masyarakat umum, seperti artikel buatan manusia (Abdullah, 2018). Dalam perspektif politik, Indonesia adalah satu kesatuan yang utuh. Namun, dari keragaman sosial, memang perlu kita akui bahwa masih ada jarak hubungan antaretnik, hal-hal yang pada umumnya mengarah pada bentrokan sosial dari seseorang yang pindah dari etnik lain (Agustian, 2019). Bentrokan antar masyarakat sering terjadi di tingkat publik. Selanjutnya, kita harus memiliki pilihan untuk mengetahui dan mengetahui tentang isu-isu seperti ini, memiliki banyak informasi tentang isu-isu, budaya, sehingga dapat berperan dalam kemajuan modernisasi. Selain itu, dengan mengikuti dan membentuk karakter negara, kita perlu memahami keyakinan kita, lebih spesifik: membingkai masyarakat umum lain yang dapat mendorong inovasi baru tanpa kehilangan kepribadian negara yang sebenarnya.

Dalam (Iskandar, 2017) keragaman sosial di Indonesia adalah sesuatu yang tidak bisa dipungkiri. Di negara-negara bagian informasi masyarakat yang berbeda, selain budaya, kebangsaan, dan negara, budaya Indonesia juga terdiri dari masyarakat yang berbeda mulai dari lokal dan merupakan pertemuan antara masyarakat yang berbeda dan pertemuan etnis yang tinggal di daerah tersebut. Sulawesi Selatan adalah salah satu bagian dari pulau Sulawesi. Pulau Sulawesi sendiri terletak di bagian timur Indonesia. Sulawesi Selatan merupakan daerah yang terletak di ujung selatan Pulau Sulawesi. Sulawesi Selatan sendiri dimiliki oleh beberapa marga, khususnya marga Bugis, Makassar, Toraja, dan Mandar. Secara geologis, ketiga marga yang ada di Sulawesi Selatan terletak di kawasan tepi pantai, sehingga dikenal sebagai marga ahli kelautan, sedangkan ketiga marga tersebut adalah marga Bugis, Makassar, dan Mandar (St Muttia, 2012). Di masa lalu ada bukti kuat bahwa pelaut dari Sulawesi Selatan menempatkan diri sebagai pelaut ahli, mereka memiliki pilihan untuk mengarungi lautan dan datang ke pulau Madagaskar, pulau yang terletak di bagian timur daratan Afrika. Perahu yang digunakan untuk berlayar disebut perahu phinisi. Prestasi ini memiliki opsi untuk memasukkannya sebagai salah satu jaringan laut. Juga, tidak kalah luar biasa dengan negara yang berbeda. Kebangkitan Islam di kabupaten ini dapat menyebar dengan cepat karena daya tarik para pelopornya, namun perlu dipahami bahwa penyebaran semacam ini adalah bahwa Islam rakyat tidak begitu kokoh jika kita membandingkannya dengan Islam masyarakat. Masyarakat yang penyebaran Islamnya dimulai dari masyarakat bawah. Banyak memberikan data tentang budaya Bugis Makassar, memberikan data bahwa penganut agama Islam Bugis Makassar adalah taat dan juga ada berbagai macam pelajaran yang masih digunakan dalam adat yang berbeda seperti Maddoja Bine. Di sana kita bisa melihat beberapa komponen Islam yang menyatu dengan keyakinan daerah masa lalu yang masih diterima hingga saat ini (Sudikna, 2021). Demikian pembahasan kali ini, khususnya tentang pengaturan keyakinan masyarakat Bugis. Bagi penghuni tertentu, praktik ini masih dianggap memiliki sifat-sifat positif yang akan terus dilestarikan kapan pun, namun adat-istiadat yang dianggap tidak pantas pada akhirnya akan berangsur-angsur hilang. Meskipun demikian, tidak dapat kita pungkiri bahwa dalam kehidupan yang mengglobal seperti sekarang ini, tentunya masih banyak adat-istiadat dari 
berbagai daerah di Indonesia yang masih dipertahankan hingga saat ini. Salah satu model adalah hal yang terus dilakukan oleh daerah setempat sebagai kebiasaan di Desa Anabanua.

\section{Metode Penelitian}

Teknik yang digunakan dalam tulisan ini adalah strategi subjektif. Teknik subjektif ini dilengkapi dengan mempersiapkan penyelidikan informasi (Hasanah, 2017). Dalam penyelidikan penelitian dan pengumpulan informasi adalah dua variabel penting. Keduanya adalah siklus yang sangat tegas dan tidak diragukan lagi saling melengkapi. Eksplorasi ini menceritakan tentang sesuatu yang mengalir secara konsisten. Strategi pemeriksaan subjektif ini menjelaskan gagasan secara keseluruhan dan gagasan akan berubah setelah menghadapi interaksi eksplorasi. Pemeriksaan subyektif juga merupakan penelitian dalam keadaan yang masuk akal dan informasi yang dikumpulkan pada umumnya bersifat subyektif. Selanjutnya eksplorasi ini disebut teknik subjektif. Strategi subjektif dapat digunakan untuk melihat keajaiban sosial yang ada, untuk situasi ini merupakan siklus dan peristiwa komunikasi sosial di Kota Anabanua, Wilayah Barru, Rezim Barru. Pemeriksaan informasi dilakukan setelah pengumpulan informasi. Artinya,

pemeriksaan akan dilakukan setelah pengumpulan informasi secara umum selesai. Perenungan seperti ini harus diselesaikan cukup lama, pertama, siklus pemeriksaan harus dilakukan secara tuntas agar judul, isu, spekulasi, dan lain-lain tidak terpaku. Kedua, untuk menekan biaya penelitian, khususnya bagi para ilmuwan yang wilayah dan tempat pemeriksaannya umumnya jauh. Sumber informasi yang didapat dalam review ini berasal dari persepsi atau persepsi terhadap item yang diteliti. Persepsi merupakan salah satu prosedur yang paling sering digunakan dalam penelitian, baik kuantitatif maupun subjektif, baik sosial maupun humanistic (Nugrahani \& Hum, 2014). Faktor utama dalam metode persepsi adalah saksi mata dan orang yang dilihat yang kemudian juga berperan sebagai penyalur data, lebih tepatnya saksi. Prosedur pengumpulan informasi berikut adalah wawancara. Rapat adalah salah satu hal utama selama eksplorasi subjektif memanfaatkan prosedur pemeriksaan informasi. Sebagai aturan umum, pertemuan terdiri dari dua bagian, khususnya penanya, untuk lebih spesifik spesialis itu sendiri dan individu yang akan ditemui. Pertemuan dipimpin dengan saksi atau warga sekitar yang mengetahui atau secara teratur mempraktikkan kebiasaan bime maddoja di Kota Anabanua, Lokal Barru, Peraturan Barru. Pada tingkat dasar, pertemuan diharapkan terjadi secara terbuka, namun harus sesuai subjek dan kondisi yang masuk akal dengan saksi. Hal ini dilakukan agar informasi yang didapat akan merata dan dapat ditentukan.

\section{Hasil dan Pembahasan}

A. Hasil dan Pembahasan

1. Tradisi Lisan Dalam Kerangka Konseptual

Ada begitu banyak ide yang dapat diandalkan untuk membantu kita memahami dan menganalisis berbagai keajaiban yang kita temukan di lapangan. Bagaimanapun, pasti tidak ada hipotesis lengkap tunggal yang dapat sepenuhnya menjelaskan keajaiban ini dengan cukup. Berikutnya adalah ide-ide berbeda yang digunakan untuk melakukan pemeriksaan ini.

2. Tradisi Lisan

Dalam buku yang berjudul Oral Verse (1977) Finnegan menjelaskan bahwa tindakan adat lisan direncanakan sebagai bagian dari kelimpahan sosial sebagai lisan dan bahwa praktek lisan telah ada cukup lama, teratur, dan memiliki tempat dengan daerah setempat menjelaskan bahwa dengan asumsi kita berpikir mendalam tentang kebiasaan lisan, kita juga dapat 
memahami perilaku sosial individu yang memilikinya (Abdullah, 2018).

3. Ritual dan Mitos

Adat adalah suatu gerakan atau berbagai kegiatan yang diterapkan oleh kebiasaan dan hukum yang berlaku di masyarakat umum yang ditandai dengan berbagai peristiwa yang sangat tahan lama yang secara konsisten terjadi secara lokal yang bersangkutan. Dalam praktik atau fungsi yang ketat, aktivitas atau perilaku umumnya terjadi. Kegiatan-kegiatan tersebut merupakan perpaduan dari amalan- amalan yang berbeda, misalnya berdo'a, sujud, qurban, makan bersama, bergerak dan bernyanyi, pawai, pertunjukan suci, puasa, renungan dan renungan (Suyanto, 2015). Menurut (Nurrachman, 2013) menjelaskan tentang fantasi, legenda adalah cerita klasik yang dianggap asli dan dianggap suci oleh pemiliknya. Fantasi itu sendiri dibandingkan dengan gambaran optimal oleh masyarakat, legenda menggabungkan pengaturan informasi, kesimpulan dan keyakinan masyarakat umum. Seperti yang ditunjukkan oleh Malinowski fantasi dapat dimanfaatkan sebagai sanksi keyakinan untuk daerah (Lessa et al., 1979). Fantasi itu sendiri memiliki kapasitas untuk menyimpan implikasi sosial yang digunakan individu untuk menguraikan pemikiran, perspektif, dan kerangka keyakinan mereka. Fantasi biasanya diidentikkan dengan keajaiban yang ketat (kerangka keyakinan). Berdasarkan uraian (Koentjaraningrat., 1994) berpendapat bahwa ada beberapa bagian penting dalam kerangka yang ketat, khususnya perasaan yang ketat; kerangka keyakinan manusia tentang keadaan dunia, yang kuat, kematian, dll; Motivasi di balik kerangka pelayanan yang ketat adalah untuk menemukan hubungan dengan dunia surgawi dan lebih jauh lagi pertemuan.

B. Pembahasan

\section{Pengertian Maddoja Bine}

Maddoja bine merupakan tradisi pertanian yang selalu dilakukan oleh para petani Bugis, tradisi tersebut bertujuan untuk menghormati Sangiang Serri, dewi padi menurut kepercayaan orang Bugis). Dari asal katanya maddoja berarti begadang atau tidak tidur, sedangkan bine berarti benih. Petani yang mengamalkan tradisi maddoja bine akan menjaga benih padi yang direndam sebelum disemai (dalam istilah seharihari masyarakat Desa Anabanua disebut ma'gugu) di sawah keesokan harinya. Seperti kue tradisional Bugis yang khusus disiapkan untuk acara Maddoja Bine. Pelaksanaan tradisi maddoja bine merupakan upaya yang dilakukan oleh masyarakat desa Anabanua untuk membujuk Sangiang Serri karena esok harinya akan dilepasliarkan namun dengan harapan akan kembali sehat saat panen telah tiba. Petani melepas Sangiang Serri sambil berdoa agar Sangiang Serri bisa kembali dalam jumlah banyak dan dalam waktu yang tidak lama. Saat itu, benih padi akan menerima iringan sesaji dan pembacaan mantra dari warga yang melaksanakan tradisi tersebut. Dengan massureq, atau membacakan surat kepada Sangiang Serri, mengingatkannya bahwa ia diutus ke dunia untuk menjalankan tugasnya sebagai sumber energi bagi kehidupan manusia.

Di sisi lain, Sangiang Serri juga akan meminta agar dirinya diperlakukan dengan baik oleh masyarakat dan mengingatkan masyarakat untuk selalu menjaga kerukunan. Oleh karena itu, Sangiang Serri hanya akan datang dan tinggal di masyarakat (petani) yang memperlakukannya dengan baik. Tradisi bine maddoja merupakan salah satu tradisi La Galigo yang dilakukan oleh para petani Bugis. Keberadaan tradisi La Galigo sangat erat kaitannya dengan kerajaan Bugis yang memiliki lembaga adat. Saat itu, galung arajangE (sawah tradisional yang dikuasai kerajaan) masih berdiri dan digunakan sebagai pusat pelaksanaan ritual pertanian. Setiap musim tanam atau 
pada saat menabur benih padi biasanya akan selalu dimulai di Galung ArajangE.

Pada saat sistem kerajaan menghilang dan digantikan dengan sistem pemerintahan Republik Indonesia, kelangsungan ritual agraria sudah mulai memudar. Namun demikian, tradisi maddoja bine sebagai benang merah bagi keberlangsungan tradisi tersebut masih dilakukan oleh sebagian besar petani Bugis, terutama yang tinggal di daerah terpencil, dan salah satu contohnya adalah masyarakat di Desa Anabanua, Kecamatan Barru, Barru. Kabupaten yang hampir $100 \%$ penduduknya adalah orang Indonesia. Bugis yang pekerjaannya sebagai petani. Ritual bine maddoja merupakan bagian dari kepercayaan (agama) petani Bugis di Dewata SeuwaE (Tuhan Yang Maha Esa). Dengan bine maddoja, orang Bugis tetap menggunakan agama lokalnya. Hal ini juga menunjukkan bahwa kepercayaan (agama) masyarakat Bugis yang memiliki berbagai tradisi hingga saat ini masih sangat menjiwai dan mempengaruhi kehidupan sosial budaya masyarakat Bugis khususnya masyarakat Bugis di Desa Anabanua Kecamatan Barru Kabupaten Barru. Bagi masyarakat di daerah tersebut, tradisi yang mereka lakukan secara turun temurun hanyalah mengikuti apa yang dilakukan nenek moyang mereka sebelumnya. Pelaksanaan maddoja bine juga merupakan bagian niskala, yaitu sebagai pengingat, cara menyimpan, melestarikan, dan menginformasikan segala pengetahuan (kearifan lokal) kepada masyarakat Bugis.

2. Pelaksanaan Maddoja Bine Dan Strukturnya

Dari penelusuran ini, ada 4 tipologi pelaksanaan maddoja bine di kalangan masyarakat Bugis, khususnya 1) maddoja bine yang dilakukan sendiri-sendiri atau sendiri-sendiri dan dibarengi dengan membaca Sureq $\mathrm{La}$ Galigo (massureq), 2) diselesaikan sendiri-sendiri atau sendiri-sendiri. Dan bergabung dengan komponen yang ketat. Islam yang biasa disinggung sebagai (barazanji) dan tidak disertai dengan membaca Sureq La Galigo, 3) diselesaikan sendiri-sendiri atau sendiri-sendiri tanpa membaca Sureq La Galigo, dan 4) dilakukan secara berjamaah dan dengan membaca Sureq La Galigo. Pada umumnya pelaksanaan maddoja bine dipisahkan menjadi tiga tahap, dimulai dengan pembukaan dengan membaca doa/mantra Sandro Wanua, membaca sureq (barazanji), dan menutup dengan membaca petisi yang tujuannya untuk keamanan bersama. Di panggung utama, pengajian dilakukan setelah benih padi yang basah kuyup ditaruh di posisi bola atau titik fokus rumah. Ada beberapa jenis perlengkapan yang digunakan untuk bea cukai seperti sumbangan, perangkat keras pedesaan, dan perangkat rias dan semuanya dipasang di posisi bola atau titik fokus rumah. Perangkat keras yang sebenarnya secara eksplisit ditujukan kepada Sangiang Serri.

Sebagai seorang wanita, dia dianggap mendapatkan kesempatan untuk berdandan, mirip dengan wanita pada umumnya. Unsur sumbangannya adalah rekko ota (daun sirih), pinang, daun paruh, benno (berih), kemenyan, sokko (nasi ketan), pallisek (lauk pauk), attello manuk (telur ayam), minya' bau, ( kelapa diblender dan dimasak, pucuk daun jati, dan kayu manis), daun mayang, pesse pelleng (lampu lilin dari kemiri).

Siklus awal adalah membaca doa atau mantra, yang dilanjutkan dengan mengkonsumsi kemenyan dan menyalakan pesse pelleng, dan menaburkan air pada benih padi. Tahap selanjutnya adalah tahap membaca sureq (huruf) atau barazanji. Sesuai yang didapat di lapangan, sureq yang selalu dibaca adalah Sureq Riuloqna Batara Master ri Lino, surat tersebut menceritakan tentang awal atau awal munculnya manusia, khususnya Batara Master sebagai manusia utama di planet ini dan Sureq Meong Palo 
Karellae yang menceritakan kisah perjalanan Sangiang Serri bergabung dengan seekor kucing bernama Meong Palo Karellae. Penjaga gerbangnya yang teguh.

Sangiang Serri memberikan syarat bahwa ia perlu tinggal di suatu ruang, khususnya penghuninya harus hidup rukun, tunduk, bermoral, dan harus secara konsisten memuji dan memanggil makhluk ilahi (Patotoe). Tahap ketiga atau penutup berisi permohonan keselamatan bersama. Permohonan itu berisi harapan bahwa apa yang coba dilakukan oleh peternak itu akan menjadi hadiah bagi keluarga mereka.

3. Fungsi Maddoja Bine

Kapasitas dalam pelaksanaan adat maddoja bine adalah sebagai adat. Kebiasaan ini sebagian besar merupakan gerakan agregat, dan difokuskan pada yang tidak mencolok/tersembunyi, tujuannya adalah untuk mendapatkan bantuan. Kebiasaan-kebiasaan ini sebagai aturan menggunakan bahasa dan tanda-tanda lambang, kontribusi. Ada beberapa unsur adat Maddoja Bine, lebih tepatnya:

a. Kemampuan Sosial Hal ini terlihat pada saat pelaksanaan Maddoja Bine yang dianggap melibatkan beberapa lapisan masyarakat karena sebelum Melakukan adat bine Maddoja, ada juga beberapa upacara atau adat pedesaan yang dilakukan, misalnya tudang sipulung. (duduk bersama dan membicarakan). Dengan melengkapi adat bine maddoja, penghuni sekitar diingatkan untuk selalu menjaga kerukunan dan kekeluargaan antar sesama sesuai $\mathrm{k}$

b. Addoja bine juga dapat menjadi wadah atau wadah persekolahan bagi daerah setempat dari kualitaskualitas sosial yang terkandung di dalamnya. Selain itu, ketika menyelesaikan adat maddoja bine, biasanya juga diawali dengan mattangak esso (mencari hari yang baik) yang bergantung pada informasi dukun atau biasa disebut kosmologi, kondisi iklim, musim. Informasi semacam ini juga dapat ditemukan di lontaraq pananrang, yang mengungkap indikasi hujan dan panas hanya sebagai penyebab kejengkelan sesekali. Maddoja bine yang dirangkai dengan massureq juga merupakan posisi penyampaian informasi yang terkandung dalam sureq yang dibaca.

c. Sebagai Sarana Korespondensi Maddoja bine juga berfungsi sebagai alat khusus adat, menempatkan Patotoe Dewata Seuwae, Tuhan Yang Maha Kuasa sebagai pengatur alam semesta. Dalam situasi khusus ini, maddoja bine juga memiliki tujuan agar orang dapat membangun hubungan dengan Patotoe, Tuhan Yang Mahakuasa. Hubungan yang terjalin antara manusia dengan Tuhan adalah hubungan yang terhormat, yaitu antara individu yang berkuasa dengan rakyat yang dikuasai.

d. Maddoja Bine Sebagai Refleksi Sejarah Manusia Bugis Kita juga dapat menganggap adat maddoja bine sebagai cerminan sejarah, khususnya masyarakat Bugis yang menggambarkan keadaan sosial individu Bugis beberapa waktu yang lalu. Suatu hari adat maddoja bine berubah menjadi gerakan adat yang khas di suatu kota. Dalam berbagai kesempatan adat maddoja bine juga berhubungan dengan keyakinan luar, seperti Islam.

\section{Kesimpulan}

Adat merupakan kesan penting dari praktik sosial-sosial bagi sekutunya. Suatu kebiasaan tidak dapat dipisahkan dari kerangka nilai yang diambil dan diterima oleh daerah setempat yang menggerakkan hati mereka untuk menyelesaikan amalan tersebut. Kerangka nilai saat ini mencerminkan arah area lokal saat ini, dan pada akhirnya akan menentukan gaya desain khusus. Misalnya, 
dalam pelaksanaan adat bine maddoja di wilayah Barru, yang mengkonsolidasikan komponen-komponen Islam (penghafalan AlQur'an dan barzanji). Hal ini menunjukkan keadaan arah individu di wilayah Barru dalam melakukan pelajaran agama Islam. Demikian pula diidentikkan dengan imajinasi daerah setempat untuk mewariskan jalan hidupnya dengan pelajaran agama yang diyakininya. Konsekuensi dari pemahaman tersebut akan menentukan konstruksi eksekusi maddoja bine. Dalam tatanan sosial, pentingnya suatu praktik adat umumnya memiliki keterkaitan antara legenda dan kerangka keyakinan (agama). Cara signifikansi dan perubahan yang paling umum dalam pelaksanaan adat di mata publik dapat dilihat sebagai dinamika sosialsosial. Perkembangan ini biasanya meninggalkan jejak perjalanan keberadaan masyarakat umum yang memiliki adat istiadat yang diidentikkan dengan kerangka kerja, kosmologi, dan kerangka informasi lokal yang ketat. Sebuah praktik tidak dapat dipisahkan dari kerangka nilai yang mengarahkan peternak untuk bertindak dalam memegang apa yang mereka sebut adat maddoja bine. Bine Maddoja direncanakan sebagai bentuk apresiasi kepada Yang Maha Kuasa dan selanjutnya sebagai apresiasi terhadap habitat asli. Dengan mengikuti kebiasaan bine maddoja, orang Bugis mempraktikkan keyakinan terdekat yang mengungkap hubungan antara alam dan Sang Pencipta. Bagaimanapun, kelanjutan latihan akan dipengaruhi oleh beberapa perhitungan yang ada di wilayah tersebut. Penilaian dari luar (isu agama dan pemerintahan) dan pembatasan interior (kerangka warisan) akan mempengaruhi adat maddoja bine dalam masyarakat Bugis. Kelanjutan adat maddoja bine merupakan suatu jenis makna atau kepentingan adat bagi orang Bugis yang menganggapnya masih bekerja dalam kehidupan mereka meskipun konstruksinya telah mengalami perubahan.

\section{Bibliografi}

Abdullah, A. P. (2018). Implementasi Penyelesaian Sengketa Tanah Melalui Lembaga Mediasi Di Kantor Pertanahan Kabupaten Gowa. Jurnal Ilmiah Ecosystem, 18(1), 1105-1115.Google Scholar

Agustian, M. (2019). Pendidikan Multikultural. Penerbit Unika Atma Jaya Jakarta. Google Scholar

Hasanah, H. (2017). Teknik-teknik observasi (sebuah alternatif metode pengumpulan data kualitatif ilmu-ilmu sosial). AtTaqaddum, 8(1), 21-46. Google Scholar

Iskandar, J. (2017). Etnobiologi dan keragaman budaya di indonesia. Umbara, 1(1). Google Scholar

Koentjaraningrat. (1994). Metode - Metode Penelitian Masyarakat Edisi Ketiga. (3rd ed.). Gramedia Pustaka Utama.

Lessa, W. A., Lessa, W. A., \& Vogt, E. Z. (1979). Reader in comparative religion: An anthropological approach. Harper Collins. Google Scholar

Nugrahani, F., \& Hum, M. (2014). Metode penelitian kualitatif. Solo: Cakra Books. Google Scholar

Nurrachman, N. (2013). The role of psychology in Indonesia's development Some past and current notions. Journal of Group Dynamics, 30, 90-97. Google Scholar

St Muttia, A. H. (2012). Proses Dalam Tradisi Perkawinan Masyarakat Bugis di Desa Pakkasalo Kecamatan Sibulue Kabupaten Bone. Makassar. Google Scholar

Sudikna, E. (2021). Akulturasi Budaya Islam Dengan Budaya Sunda Dalam Tradisi Misalin Di Desa Cimaragas Ciamis. Google Scholar

Suyanto, B. (2015). Metode Penelitian Sosial: 
Edika Syamsurya

Berbagai Alternatif Pendekatan.

Prenada Media. Google Scholar

\section{Copyright holder :}

Edika Syamsurya (2021).

First publication right :

Action Research Literate

This article is licensed under:

(c) (i) (?) 